\title{
Preliminary study of an ancient earthquake-proof construction technique monitoring via an innovative structural health monitoring system
}

\author{
Carmelo Scuro' ${ }^{1}$, Domenico L. Carnì ${ }^{2}$, Francesco Lamonaca², Renato S. Olivito ${ }^{3}$, Gabriele Milani ${ }^{4}$ \\ ${ }^{1}$ Department of Physics, University of Calabria, 87036 Rende (CS), Italy \\ 2 DIMES - Department of Informatics Modelling Electronics and Systems Science, University of Calabria, 87036 Rende (CS), Italy \\ ${ }^{3}$ DINCI - Department of Civil Engeneering, University of Calabria, 87036 Rende (CS), Italy \\ ${ }^{4}$ Department of Architecture, Built Environment and Construction Engineering, Technical University of Milan, 20133 Milan, Italy
}

\begin{abstract}
The historical and cultural heritage analysis of the Italian territory is of primary importance since this region is one of the richest in the world and can enrich our knowledge in different fields. In fact, in the field of structural engineering, a new discovery was made in Calabria, in the south of Italy. By investigating various architectural treatises related to earthquake-proof constructions, new knowledge was gained through analysing buildings constructed with fictile tubules bricks. Among them is an unprecedented anti-seismic construction technique patented by Pasquale Frezza, which has been widely used in southern Calabria. To prevent the collapse of the attendant structures, an innovative method for monitoring and obtaining the mechanical properties of these structures in real time while minimising the measurement uncertainty is proposed in this paper.
\end{abstract}

\section{Section: RESEARCH PAPER}

Keywords: Anti-seismic technique; experimental test; numerical analysis; structural health monitoring systems; measurement accuracy

Citation: Carmelo Scuro, Domenico Luca Carnì, Francesco Lamonaca, Renato Sante Olivito, Gabriele Milani, Preliminary study of an ancient earthquake-proof construction technique monitoring by an innovative structural health monitoring system, Acta IMEKO, vol. 10, no. 1, article 8, March 2021, identifier: IMEKOACTA-10 (2021)-01-08

Editor: Eulalia Balestrieri, University of Sannio, Italy

Received April 22, 2020; In final form June 16, 2020; Published March 2021

Copyright: This is an open-access article distributed under the terms of the Creative Commons Attribution 3.0 License, which permits unrestricted use, distribution, and reproduction in any medium, provided the original author and source are credited.

Corresponding author: Carmelo Scuro, e-mail: carmelo.scuro@unical.it

\section{INTRODUCTION}

In the safeguarding and prevention of the possible collapse of structures of historical interest, the collection of information relating to the quality of the construction materials, the environmental actions, the propensity for an alteration of a single component or of the structure as a whole due to a loss of material strength over time or accident-related events is of fundamental importance [1]-[3].

Structural health monitoring (SHM) systems guarantee the characterisation, identification, and detection of the evolution of damage for different types of structures [4]. In the field of structural monitoring, SHM systems consist of two main parts: a data logger that allows for the transmission and recording of information, and the acquisition system, which is used for evaluating the different physical quantities [5]. Specifically, the main information provided by the SHM system includes temperature, displacement, strain, acceleration, tensile stress, and compressive strength data [6]. Generally, SHM systems are placed in structures in a non-invasive manner, using a reversible process incorporating sensors. Here, the sensors are placed in highly precise control points of the structure in order to minimise unnecessary costs and information acquisition [1], [7]. Following a check, the useful information acquired by the sensors are used in mathematical numerical models of the structures to determine the evolution of any possible damage and safety issues [8]. In recent years, structural monitoring systems have been improved by applying the internet of things (IoT) paradigm. This is because in this paradigm, each node is capable of processing, detecting, and transmitting data. The information is transmitted through an internet connection and stored in a cloud before being processed by distributed systems functionalised via a big data paradigm [9].

Safeguarding new discoveries related to construction techniques is the ultimate aim of researchers, both in terms of structural engineering and the field of historic heritage, where the 
structures must be preserved from damage and collapse for future generations. The monitoring of historical buildings in seismic areas is a prevalent issue in Italy due to the richness of the nation's historical cultural heritage, which cannot be investigated through invasive tests. Typically, the general SHM of churches or palaces is evaluated via dynamic analyses. This type of monitoring allows for the mechanical parameters functionalised for future restoration activities to be obtained, and for the interaction between the static action and the control of possible changes in behaviour to be evaluated. Provided the construction techniques are known and the types of masonry are well-defined, it is possible to define an interaction model of the structure. However, in the case of an unknown structure or a new structure with no available information, this is not possible [10][12].

Most of the historic anti-seismic constructions of Calabria were built using rubble stone and brick masonry [13] and were frequently composed of various layers with little or no connection between them and built using various raw materials (bricks, stone or fictile tubules [14], [15]) and largely poor mortars.

This paper presents the results of the total and partial destructive tests carried out on two replicas of historic masonry specimens constructed in accordance with the patent of the engineer, Pasquale Frezza. A preliminary study was carried out in relation to the use of an SHM system placed on the ancient antiseismic structures that appeared from the beginning of the $1900 \mathrm{~s}$ [16]. Specifically, the paper is focused on earthquake-proof wooden frame structures made with common brick and fictile tubules [17]. In the SHM system design, particular importance was afforded to the definition of the mathematical model of the structure for the calculation of the structural solicitations in accordance with the Italian technical standards. The possibility of having a well-defined numerical model allows for real-time analysis based on the displacement and stress data recorded during the monitoring. This has been carried out by various authors, not only in terms of new structures such as bridges [18] but also in terms of the study and construction of large-scale monitoring systems for urban centres [19]-[21].

The remainder of the paper is organised as follows. Sections 1 and 2 outline the theory of structural mechanics used in order to calculate the shear strength in the specimens before an experimental test is introduced and the results explained. In section 3, the numerical model obtained via finite element Abaqus software is proposed before the experimental testbed is described and the measurement accuracy determined in sections 4 and 5 and the conclusions drawn in section 6 .

\section{CRITERIA FOR THE SHEAR STRENGTH PREDICTION OF PIERS}

Various simplified models are proposed in the relevant literature in relation to describing the damage that may occur in masonry piers. These models are based on the (inaccurate) evaluation of the local/mean stress generated by forces applied on pre-identified points/sections of the pier [22]. The most frequent failure modes that occur in piers are rocking/crushing, bed joint sliding, and diagonal cracking.

For the diagonal cracking failure mode, two models are generally adopted to describe it [23], [24]. These models are used to describe different types of masonry and often provide different strength values, which is the case with the Mann and Müller model and the Turnšek and Čačovič model. In the former

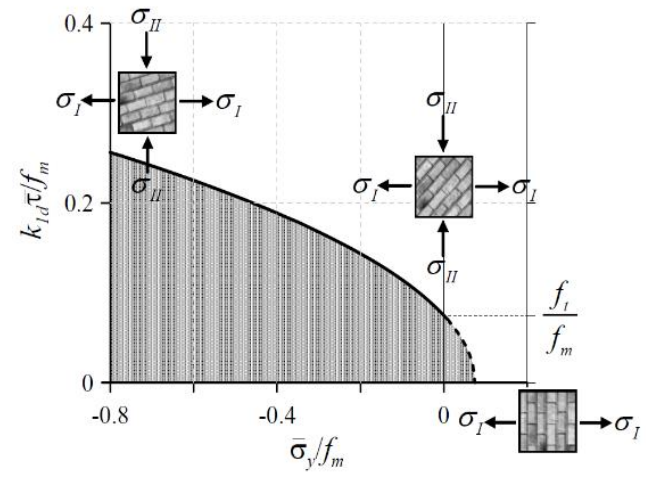

Figure 1. The failure criteria of Turnšek and Čačovič's model for masonry piers, represented in the resolved stress plane [21].

model, the limit strength domain is defined by means of 'local'type parameters relating to the individual materials that comprise the masonry (mortar and bricks), such as the cohesion and friction coefficient in the mortar joints and the tensile strength of the block of masonry under analysis [23]. In general, these two types of parameter are obtained experimentally, and the individuation of the cohesion and friction coefficients can prove difficult for specific masonry, such as that used in fictile tubules. Meanwhile, in the Turnšek and Čačovič model, the domain is defined through a single parameter of the material, i.e. the tensile strength of the masonry, which is generally determined via a diagonal compression test [24].

The model proposed by Mann and Müller describes the masonry as a composite material and considers the development of the cracks, separately, along the brick and mortar joints, while that proposed by Turnšek and Čačovič considers the masonry as an equivalent isotropic material and indistinctly describes the development of damage along the principal stress directions [25]. In studying the area of diagonal cracking, the above two models are generally recognised as the two main types.

However, the application of the Mann and Müller model to a masonry wall made with bricks and fictile tubules can prove difficult. The model is based on two main hypotheses:

(i) the mechanical properties of the head joints are negligible, and in the case in question, the bricks have a square section;

(ii) bricks are much stiffer than mortar joints, but the tubules are hollow and have a cylindrical conformation, and this hypothesis cannot be satisfied.

For these reasons, it was decided to use Turnšek and Čačovič's model, which, as noted, considers the masonry as an isotropic material. Here, the reference stress $\sigma_{\mathrm{c}}$ and the maximum principal stress acting at the centre of the pier $\sigma_{\mathrm{I}}$ must not exceed the tensile strength of the masonry $f_{t}$. The latter parameter is assumed to be constant in any loading direction (isotropic limit stress domain) [26]. This is possible since, in previous works, the authors carried out a homogenisation of the materials from which the wall was made [27].

Here, the maximum principal stress at the centre of the pier was calculated using the following equation:

$$
\sigma_{I}=\frac{\overline{\sigma_{y}}}{2}+\sqrt{\left(k_{1 d} \bar{\tau}\right)^{2}+\left(\frac{\overline{\sigma_{y}}}{2}\right)^{2}}
$$

where $\bar{\tau}$ and $\overline{\sigma_{y}}$ are respectively the mean shear and the normal stresses acting on the cross section of the pier and $k_{1 d}$ is the ratio of the shear stress at the centre of the pier to the mean shear 


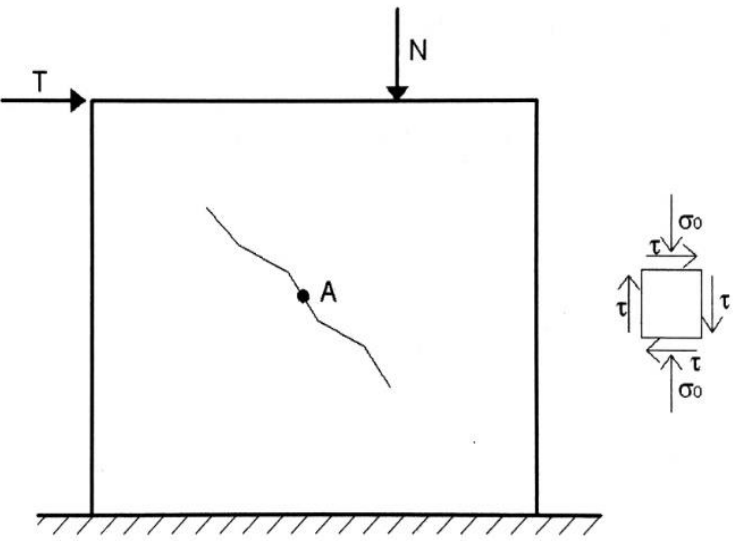

Figure 2. Adopted schematisation of the masonry block.

stress [24]. The failure criteria for masonry piers, which are represented in the resolved stress plane, are shown in Figure 1.

In the new Italian technical standards (document C8.7.1.3.1.1 7/2019) Turnšek and Čačovič's formulation is simplified in order to obtain the shear strength value of the masonry pier. Figure 2 shows the adopted schematisation of the masonry block.

The normal and tangential stress was calculated at point A using the following equations:

$$
\begin{gathered}
\sigma_{0}=\frac{N}{l \cdot t} \\
\tau_{0}=\frac{T}{l \cdot t}
\end{gathered}
$$

where $T$ and $N$ are respectively the shear and normal force applied to the masonry block and $l$ and $k$ are the length and thickness, respectively, of the masonry. The stress state at point $A$ is represented by Mohr's circle in Figure 3, as characterised by centre $C$ and radius $R$, which are expressed by (4) and (5):

$$
\begin{aligned}
& C=\frac{\sigma_{\mathrm{O}}}{2} \\
& R=\sqrt{\left(\frac{\sigma_{0}}{2}\right)^{2}+\tau^{2}}
\end{aligned}
$$

The principal tensile stress that occurs in the masonry could be obtained using the following equation:

$$
\sigma_{t}=C-R=\frac{\sigma_{0}}{2}-\sqrt{\left(\frac{\sigma_{0}}{2}\right)^{2}+\tau^{2}}
$$

squaring (6) and simplifying it, we obtain:

$$
\tau^{2}=\sigma_{t}^{2}-\sigma_{t} \cdot \sigma_{0}
$$

If $\sigma_{t}$ (tensile stress in the masonry) is equal to $f_{t}$, the tensile strength of the masonry is imposed in terms of a limit domain of Turnšek and Čačovič's formulation and $\tau=b \cdot \tau_{0}$, (7) becomes:

$$
\tau_{0}=\frac{f_{t}}{b} \sqrt{1+\frac{\sigma_{0}}{t}}
$$

Multiplying the area of the section, the shear strength of the masonry pier could be obtained:

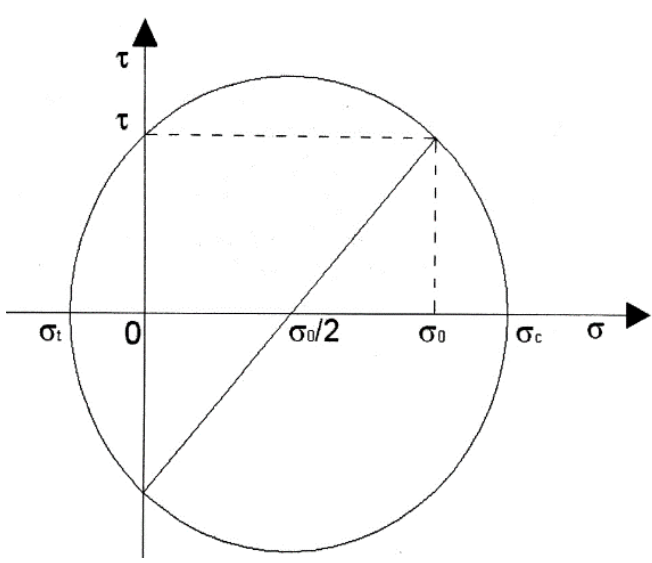

Figure 3. Tensile state at point $A$.

$$
V_{s}=\frac{f_{t} \cdot \cdot \cdot t}{b} \sqrt{1+\frac{\sigma_{0}}{t}}=\frac{1.5 \cdot l \cdot t \cdot \tau_{0 d}}{b} \sqrt{1+\frac{\sigma_{0}}{1.5 \cdot \tau_{0 d}}}
$$

where $V_{s}$ is the shear strength of the masonry pier obtained for exceeding the limit domain, $f_{t}$ is the tensile strength of the masonry, $b$ is a coefficient that takes into account the slenderness of the element and is the ratio between the height and length of the pier, with its value in the range of $1-1.5$, and $\tau_{0 d}$ is the reference shear strength.

\section{EXPERIMENTAL CAMPAIGN}

The experimental campaign was conducted in the laboratories of the University of Calabria. Using the same construction process, two masonry walls were fabricated following the patent of the engineer, Pasquale Frezza [28]. The first was tested using a diagonal compression test and was stopped after the specimen had collapsed. The second specimen was tested in the same way but was first damaged and then repaired using a basalt fibrereinforced cementitious matrix (B-FRCM). Following this, the test was repeated until the collapse of the reinforced masonry wall.

\subsection{Preparation of the specimens}

The dimensions of the two specimen walls were $60 \times 60 \times 15$ $\mathrm{cm}^{3}$. The external timber frame was constructed in a carpentry workshop and consisted of four poplar beams with a cross section of $15 \times 5 \mathrm{~cm}^{2}$ (poplar wood is a typical building material used for constructions in Calabria). The connection between any contiguous beams was ensured by cutting their extremities to produce half-lap fastenings before attaching them using four iron bolts.

After the outer timber frame was built, the inner masonry wall was created. Here, the bricks used had a square cross section of $5.5 \mathrm{~cm}$ per side and a height of $13 \mathrm{~cm}$. Meanwhile, the fictile tubules were new nomenclating fictile tubules (NFTs) [27], since these are produced in a pottery industry using faster, more innovative techniques before being refined on the potter's wheel. The tubules had the same height as the bricks $(13 \mathrm{~cm})$ and a thickness of $6 \mathrm{~mm}$ (Figure 4, Figure 5). The mortar had a compressive strength of around $2.5 \mathrm{MPa}$, corresponding to that labelled as M2.5 bastarda according to Table 11.10.IV of the 2008 Italian Building Code. This specific mortar consists of one part cement, two parts lime mortar, and nine parts sand.

The specimen wall was completed by casting a 2 -cm-thick layer of mortar to cover the tips of the fictile tubules (Figure 6). 


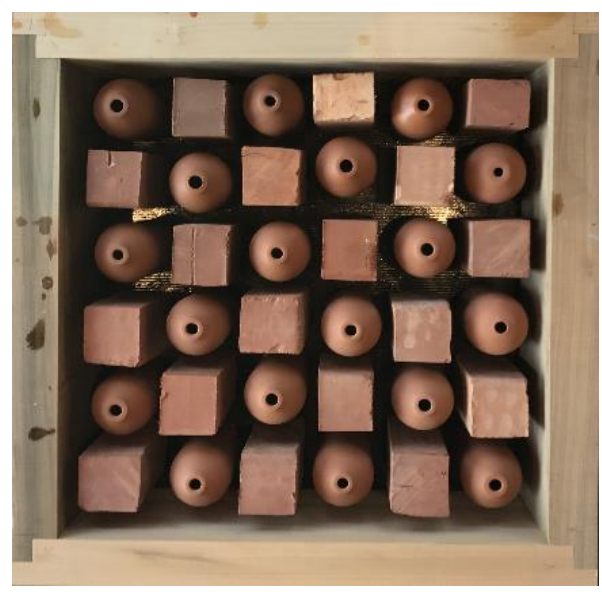

Figure 4. Arrangement of bricks and NFTs in the timber frame.

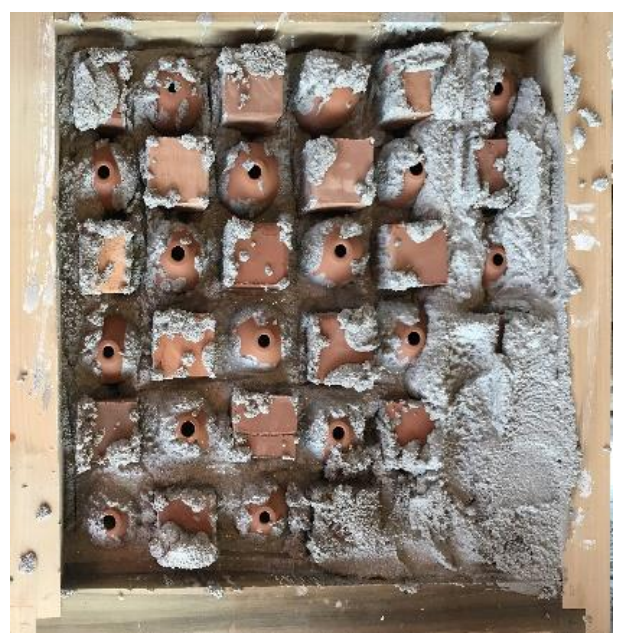

Figure 5. Mortar casting.

\subsection{Diagonal compressive test on the first specimen}

The diagonal compressive test was carried out by rotating the specimen wall by $45^{\circ}$ before two steel caps were placed on the specimen, one at the bottom for support and the other at the top for uniformly distributing the load. The speed of the test was $0.5 \mathrm{~mm} / \mathrm{s}$. Two pairs of transducers were applied to the masonry specimen to further monitor the relative displacements. Here, the transducers labelled LVDT0 measured the vertical displacements between two bricks, while those labelled LVDT1 measured the horizontal displacements between two fictile tubules (Figure 7).

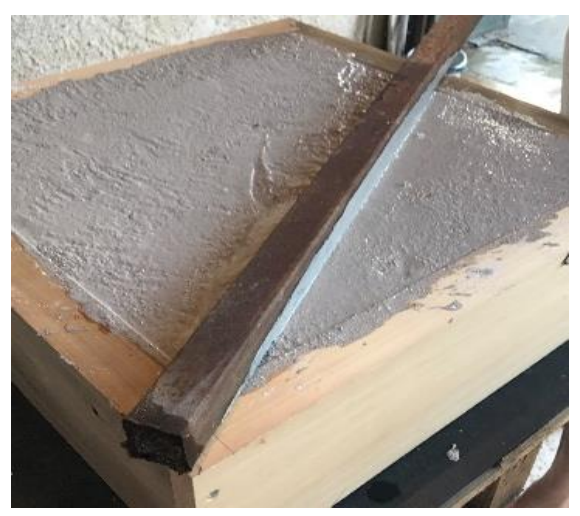

Figure 6. Creation of the upper layer of mortar.

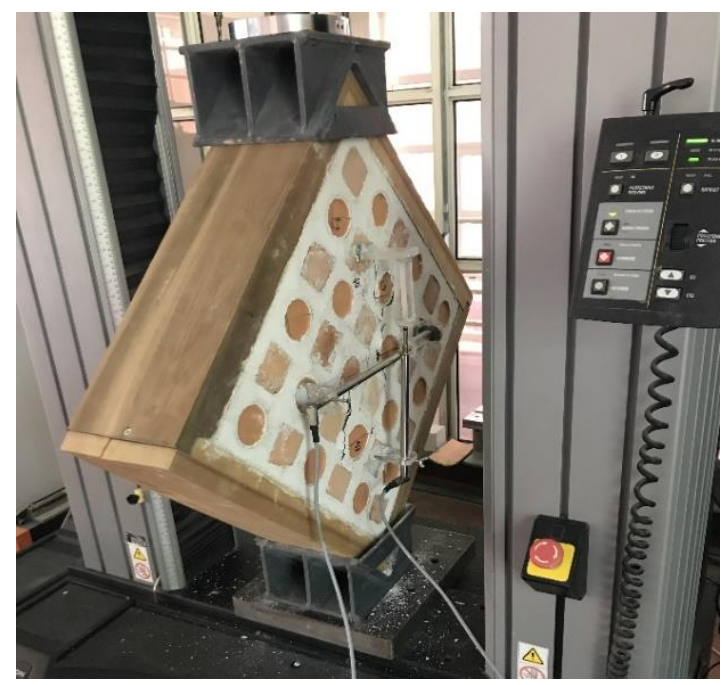

Figure 7. Set up of the test.

Another transducer with the same characteristics as those used for calculating the displacements of the masonry was positioned near the upper part of the load cell in order to measure the lowering of the cross member of the test machine.

The load displacement diagram is presented in Figure 8. Here, following a linear elastic branch up to $80 \%$ of the maximum load, the elastic modulus decreased until reaching a plateau, where the peak load was attained and was found to be $51.48 \mathrm{kN}$. At this load value, the displacement of the load cell, as recorded by the third transducer, was $11.526 \mathrm{~mm}$. The hardening branch was most likely due to the friction between the mortar and the fictile tubules elements, as well as to the overall compressive stress state of the specimen wall.

The shear strength of the wall $S_{s}$ was evaluated using (10), as was suggested in [29]:

$$
S_{S}=\frac{0.707 \cdot P}{A_{n}}
$$

where $P$ is the peak load and $A_{n}$ is the net area, which was evaluated using (11):

$$
A_{n}=\left(\frac{w+b}{2}\right) t \cdot n
$$

where $w$ and $b$ are the width and the height of the specimen, respectively (here considered as the dimensions of the masonry

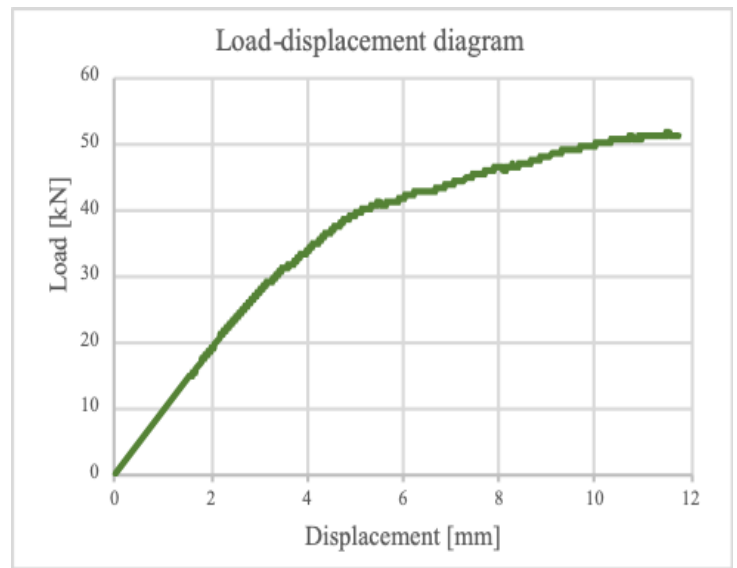

Figure 8. Load displacement diagram. 


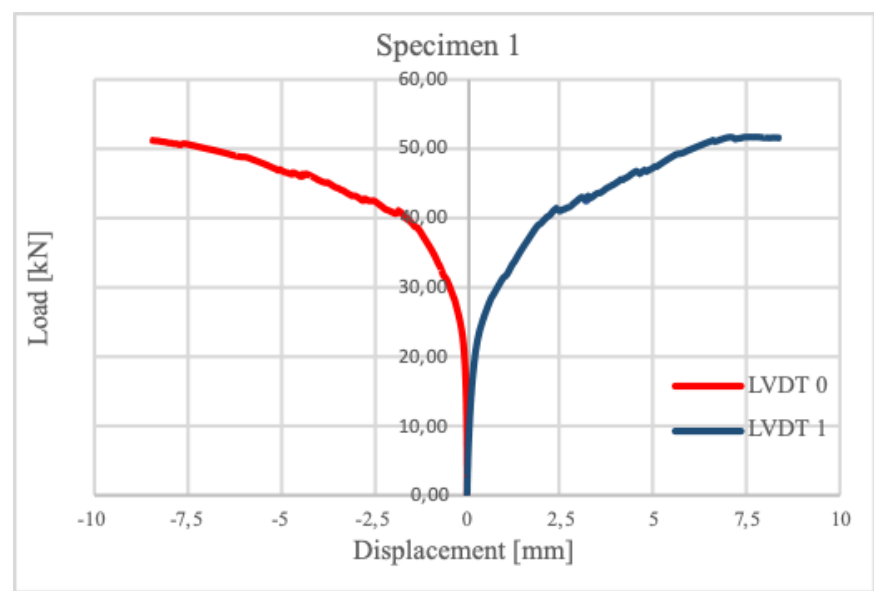

Figure 9. Load vs. displacement diagrams of the transducers for specimen 1.

inner core, both $=50 \mathrm{~cm}), t$ is the thickness of the specimen $(15 \mathrm{~cm})$, and $n$ is a coefficient related to the rate of voids in the specimen (here considered to be 0.6 , where 1 corresponds to a wall with no voids). The shear strength corresponding to the peak load was $0.81 \mathrm{MPa}$.

Figure 9 shows the load vs. displacement diagrams recorded via transducers LVDT0 and LVDT1 during the test.

\subsection{Diagonal compressive test on the second specimen}

The same test set up was used to analyse specimen number 2 . In this case, the test was stopped at the formation of the first damage and when the diagram arrived at the end of a linear elastic branch. The recorded peak load was $46.77 \mathrm{kN}$ (Figure 10).

The shear strength of the wall $S_{s}$ was evaluated using Eq. 9, with the value corresponding to the peak loads $=0.73 \mathrm{MPa}$.

When damage began to develop in the specimen, the test was stopped, and the specimen was repaired and reinforced. Three B-FRCM strips of $100 \mathrm{~mm}$ were placed at the side of the wall featuring a 2-cm layer of mortar (Figure 11). The B-FRCM strips were chosen since compatibility with the support was ensured and since they are characterised by a tensile strength and a Young's modulus of $134 \mathrm{MPa}$ and $19 \mathrm{GPa}$, respectively, while those for basalt fibres are generally $301.5 \mathrm{MPa}$ and $16 \mathrm{GPa}$ [11]. In order to measure the strains on the strips, two strain gauges were applied to the central strip in relation to the fibres perpendicular to the cracks. Following this, the test was repeated on the reinforced specimen until it collapsed.

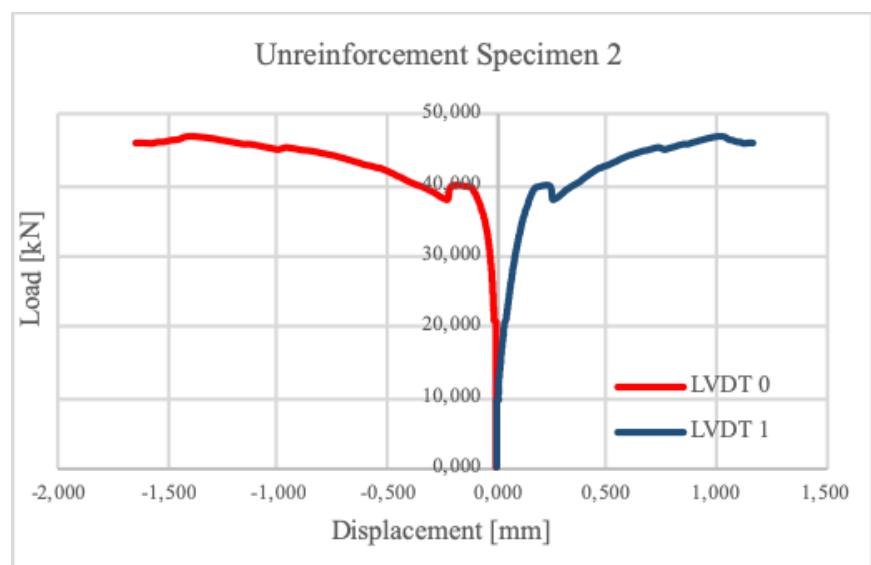

Figure 10. Load vs. displacement diagrams of transducers for unreinforced specimen 2.
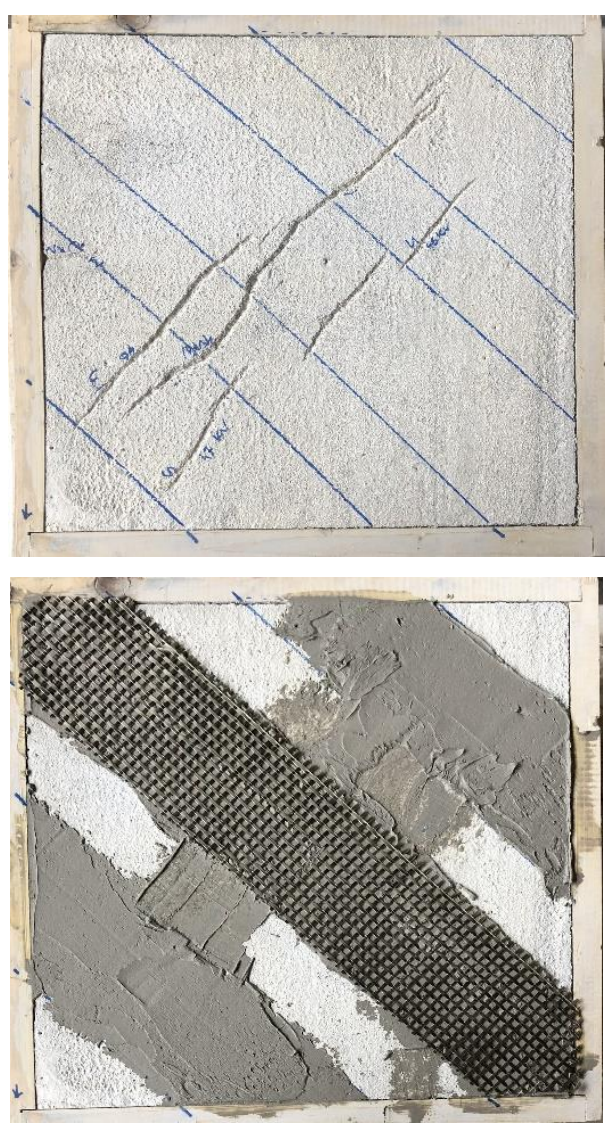

Figure 11. Specimen 2 before and after reinforcement.

The maximum value of the load recorded during the reinforcement test was $66.48 \mathrm{kN}$ (Figure 12). At this load value, a failure of the B-FRCM reinforcement occurred [30], which was due to the debonding following the cohesive failure of the substrate (Figure 13).

To obtain the value of the strain that occurred in the reinforced basalt fibre during the test, two strain gauges were applied to the central part of the diagonal B-FRCM. A strain gauge is a device commonly used to obtain the strain on a specimen subjected to different types of stress, such as compression or tensile stress.

The strain gauges used here were the most common type and consisted of an insulating flexible backing that exhibited a

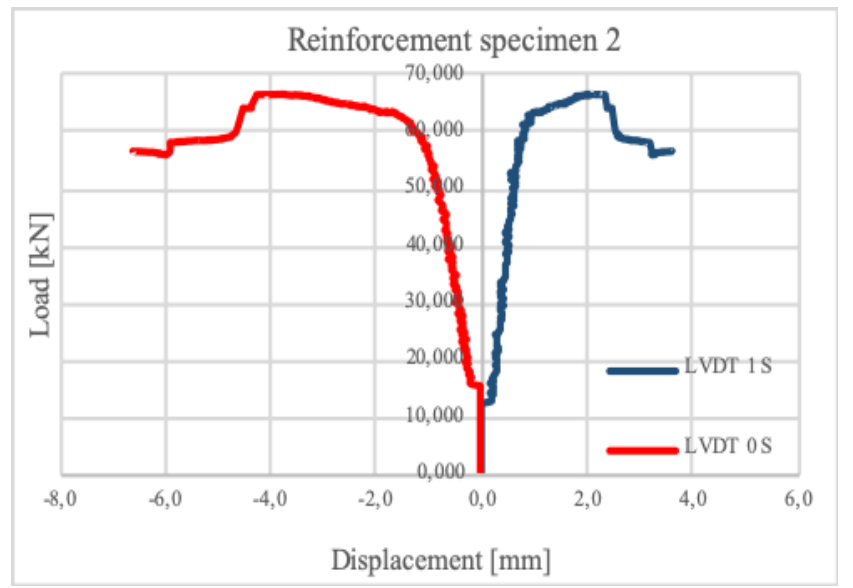

Figure 12. Load vs. displacement diagrams of the transducers for reinforcement of specimen 2 . 


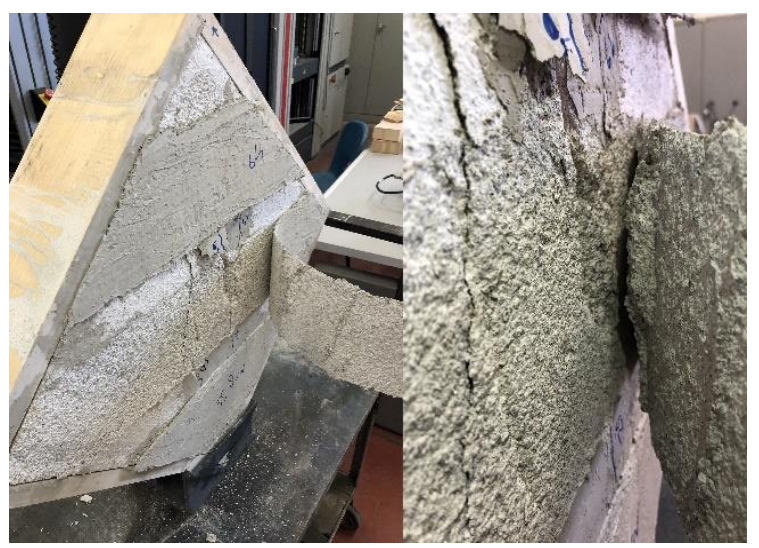

Figure 13. Collapse of the reinforcement strip.

metallic foil pattern. The gauge was positioned on the B-FRCM strip using a cyanoacrylate adhesive. When basalt fibres are deformed, the foil is deformed, causing the electrical resistance to change, with this change, generally measured using a Wheatstone bridge, related to the strain imposed by the quantity known as the gauge factor.

Figure 14 shows the shear stress vs. strain diagram obtained during the test conducted on the reinforced specimen. Here, the shear stress was evaluated using Eq. 9 and was found to be $1.04 \mathrm{MPa}$.

The average value of the strain recorded during the test by the two strain gauges was $3.25[\mu \mathrm{m} / \mathrm{m}]$ E-3. This value was in line with that prescribed by the manufacturer of the fibre, that is, a range of $3-3.5[\mu \mathrm{m} / \mathrm{m}]$ E-3.

\section{NUMERICAL MODEL}

The principal goals in the creation of the numerical model were repeating the diagonal compressive test and simulating the behaviour of the structures in question. Here, the commercial computer-aided design software, Rhinoceros, was used to create a simplified geometrical model of the specimen. The outer timber frame, the common bricks, and the fictile tubules were modelled separately in terms of a solid composed of a surface characterised by a normal vector facing out [31]. Following this, the single part was assembled and imported into the commercial finite element software, Abaqus, where the analysis was conducted.

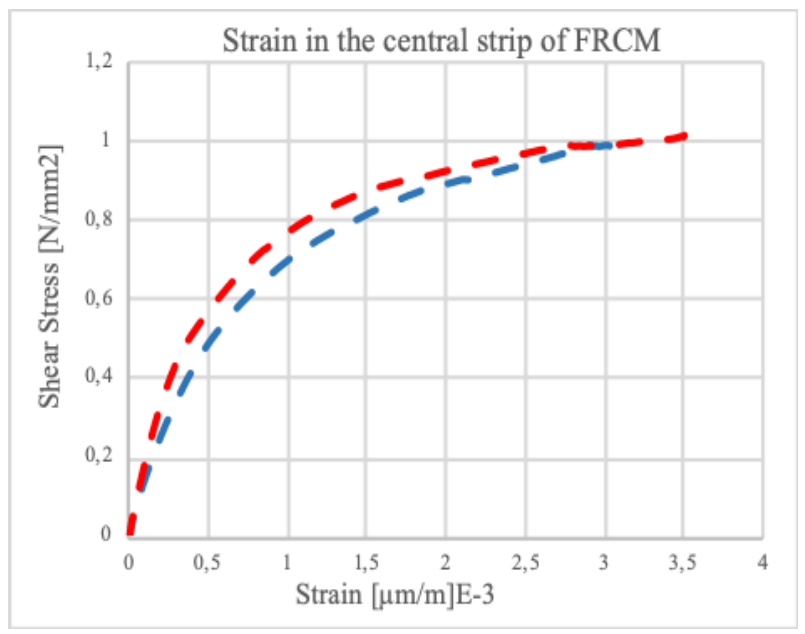

Figure 14. Shear stress vs. strain diagram.
The common bricks and the timber frame were meshed using hexahedral C3D8 finite elements (classified as C3D8 in Abaqus), while tetrahedral elements (C3D4) were used for the fictile tubules and the inner mortar. The final model created was composed of a total of 47,093 nodes and 165,710 elements $(1,120$ C3D 8 and 164,590 C3D4) [14]. To calculate the behaviour of the relevant bonds, a tie constraint was imposed between the mortar and the fictile tubules and bricks, while a general contact was imposed to simulate the interaction between the timber frame and the mortar, returning a friction coefficient of 0.8 [32].

The materials of the common bricks and the timber frame were modelled in terms of linear elastic materials. Specifically, the orthotropy of the wood was not considered but was imposed as an isotropic material to simplify the final model and to reduce the computational burden [33]. This was possible because, during the experimental test, the timber frame experienced damage after the mortar did and did not undergo collapse. In fact, the fictile tubules and the mortar were simulated using the concrete damaged plasticity (CDP) material model available in the Abaqus library. Originally, the CDP model was created to simulate the behaviour of concrete under fairly low confining pressures and, given the damage that develops here, the model's general formulation means it can be used in the simulation of a broader range of materials [34]-[36]. Table 1 lists the Young's modulus values and the Poisson's ratios for the four materials considered. Meanwhile, Table 2 and Table 3 present the tensile constitutive law values for fictile tubules and mortar, respectively, as expressed in terms of displacements and stresses.

The ultimate displacement of the materials was imposed with a high value in order to successfully complete the analysis without affecting the structural response of the materials. A damage parameter of 0.99 was set for both the mortar and the clay of the tubules in proximity to a plastic displacement of 0.03 $\mathrm{mm}$.

The comparison between the numerical and experimental load displacement diagrams is shown in Figure 15. The numerical analysis satisfactorily estimated the linear elastic branch of the graph, but the peak load attained was $8 \%$ higher than the experimental load (55.54 vs. $51.48 \mathrm{kN})$. In addition, the numerical analysis was halted for an ultimate displacement that

Table 1. Young's modulus and Poisson's ratio values.

\begin{tabular}{ccc}
\hline Material & Young's modulus in MPa & Poisson's ratio \\
\hline Wood & 270 & 0.00 \\
Clay (bricks) & 1290 & 0.15 \\
Clay (tubules) & 4800 & 0.15 \\
Mortar & 275 & 0.20
\end{tabular}

Table 2. Tensile constitutive law values for mortar

\begin{tabular}{cc}
\hline Tensile stress in MPa & Plastic displacement in $\mathbf{~ m m}$ \\
\hline 0.4200 & 0.00 \\
0.0005 & 0.03 \\
0.0005 & 6.50 \\
\hline
\end{tabular}

Table 3. Tensile constitutive law values for tubule clay.

\begin{tabular}{cc}
\hline Tensile stress in MPa & Plastic displacement in $\mathbf{~ m m}$ \\
\hline 2.7500 & 0.000 \\
0.0005 & 0.058 \\
0.0005 & 10.75 \\
\hline
\end{tabular}




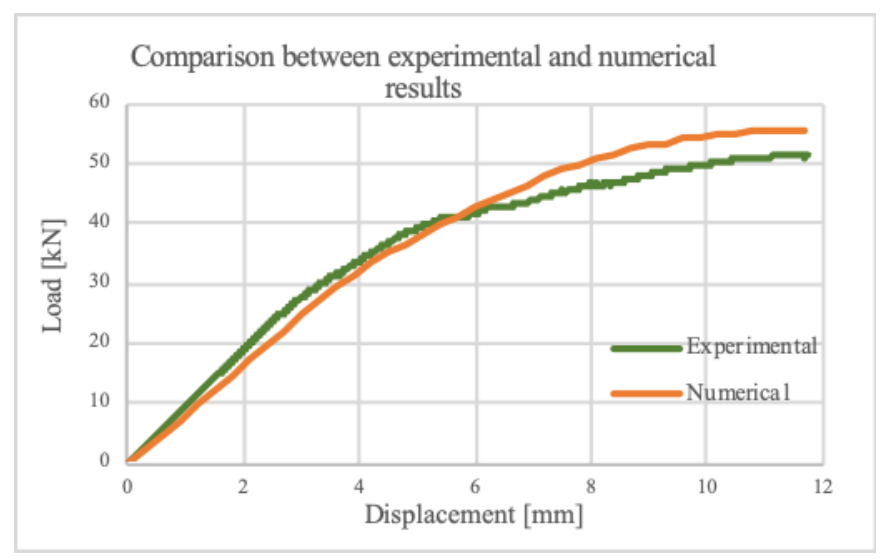

Figure 15. Shear stress vs. strain diagram comparison.

was close to that related to the load peak recorded during the experimental test. In fact, the displacement obtained by the numerical model was $11.700 \mathrm{~mm}$, while the experimental displacement was $11.526 \mathrm{~mm}$.

The damage in the numerical model corresponded to the experimental outcome, while more cracks were present at the top, as were four single cracks originating at the mid-section of each timber beam. Given the overall fair correspondence in terms of crack patterns, it can be assumed that these four single cracks appeared only for numerical reasons, meaning they played no significant role in the overall response of the numerical model (Figure 16).

\section{EXPERIMENTAL TESTBED AND MEASUREMENT ACCURACY}

Two different acquisition systems (ASs) were used to monitor the displacements in the case of the first specimen, and the displacement and the strain of the basalt fibre in the case of the second specimen.

The first AS was composed of the following: three linear variable differential transformers (LVDTs) [37] used for monitoring the horizontal and vertical displacement and connected to a data acquisition system (DAQ, Spider-8), which transmitted the data to a computer [38]. Meanwhile, the second AS was composed of two LVDTs and two strain gauges, which were connected to a DAQ 5100B micro-measurement system. The second DAQ allowed for the real-time acquisition of two different types of data, which were transmitted to a computer such that they could be processed in real time, while the LVDTs used to monitor the displacement in the masonry wall were the WA-T $50 \mathrm{~mm}$ type and were procured by HBM. The WA-T displacement transducers were of a probe type and incorporated
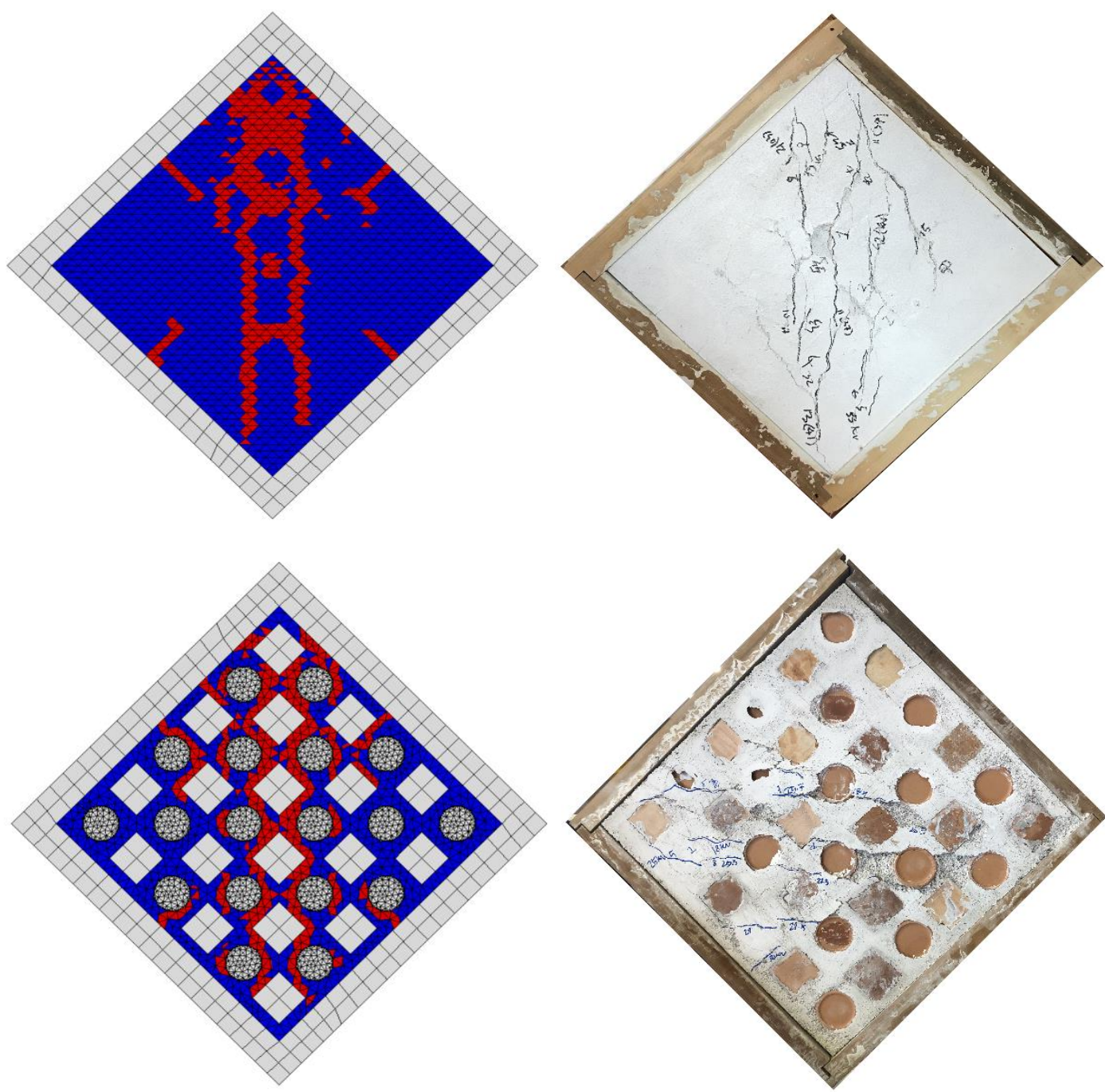

Figure 16. Comparison of crack development in the back and front side of the numerical model and the experimental specimen wall. 
an active quarter bridge circuit based on the differential inductor principle. The bridge was also directly integrated in the sensor to create a full bridge circuit for easy connection of the WA-T transducer to the DAQ.

The linearity variation in relation to the nominal value was $\pm 1 \%$, while the range of displacement that can be measured using this type of LVDTs is $0-50 \mathrm{~mm}$ [39]. Meanwhile, the Spider 8 DAQ was operated by an individual operator, who ensured a simultaneous measurement acquisition, a high sampling rate at a 16-bit resolution, and selectable digital filters, while the linearity variation in relation to the nominal value was $\pm 0.05 \%$.

System 5000 Model 5100B scanners acquire test data within $1 \mathrm{~ms}$ from up to 1,200 channels at scan intervals as short as $0.02 \mathrm{~s}$. This ensures both obtaining more accurate test results and having the ability to capture data under static loading conditions immediately before the failure of the structure being monitored. The strain gauge cards integrated included a built-in bridge completion for quarter and half bridges and a constant voltage power supply for $0.0,0.5,1.0,2.0,5.0$, and 10.0 VDC bridge excitation. The A/D converter featured a 16-bit successive approximation converter with a total conversion time per reading of $40 \mu \mathrm{s}$ [40]. The $5100 \mathrm{~B}$ operates with $1 \mathrm{~ms}$ per scan, with 50 complete scans per s the typical usage. Concurrent scanning was adopted for all scanners, with the input channels in each scanner scanned sequentially at $0.04-\mathrm{ms}$ intervals and stored in random access memory within a $1 \mathrm{~ms}$ window.

The strain gauges used were the PFL-10-1 type, which are polyester linear gauges with mild steel compensation, specifically, a foil strain gauge with a polyester resin backing. This type of strain gauge features 2 -cm pre-attached lead wires, a strain limit of $2 \%(20,000 \mu \mathrm{s})$, an operational temperature of $20^{\circ} \mathrm{C}-80{ }^{\circ} \mathrm{C}$, and a nominal resistance of $120 \Omega$.

The main problem that emerged during the second test on the second specimen was the return of the LVDT data. As indicated by the elastic branch of the load vs. displacement diagram presented in Figure 12, there was a disturbance caused by a noise that was due to the DAQ. Meanwhile, the data acquired by the channels dedicated to the strain gauges did not present this problem. As such, a spline fitness function was implemented to minimise the effect of the noise, thus preserving the linearity of the load vs. displacement graphs to obtain new diagrams, which are presented in Figure 17. Here, a cubic spline interpolation algorithm was used on the acquired data, with the spline function smoothing the random trend due to the noise, which allowed for highlighting the load vs. displacement trend.

The linearity variation in relation to the nominal value of the DAQ was $\pm 0.05 \%$, and, as such, was negligible in the evaluation of the measurement accuracy with respect to the sensor linear characteristics. However, in terms of the linearity variation in relation to the nominal value for the LVDTs, this was \pm 0.500 $\mathrm{mm}$ [39], [40]. This value had to be reduced by dividing it by $\sqrt{3}$ and identifying a range of $\pm 0.288 \mathrm{~mm}$ [41].

\section{CONCLUSIONS}

The principal aim of this paper was to conduct preliminary research into the reliability and monitoring under dynamic loads of the technique patented by Pasquale Frezza. This type of antiseismic construction consists of masonry walls built with bricks and fictile tubules, arranged in a staggered and alternating manner within a timber wooden frame.

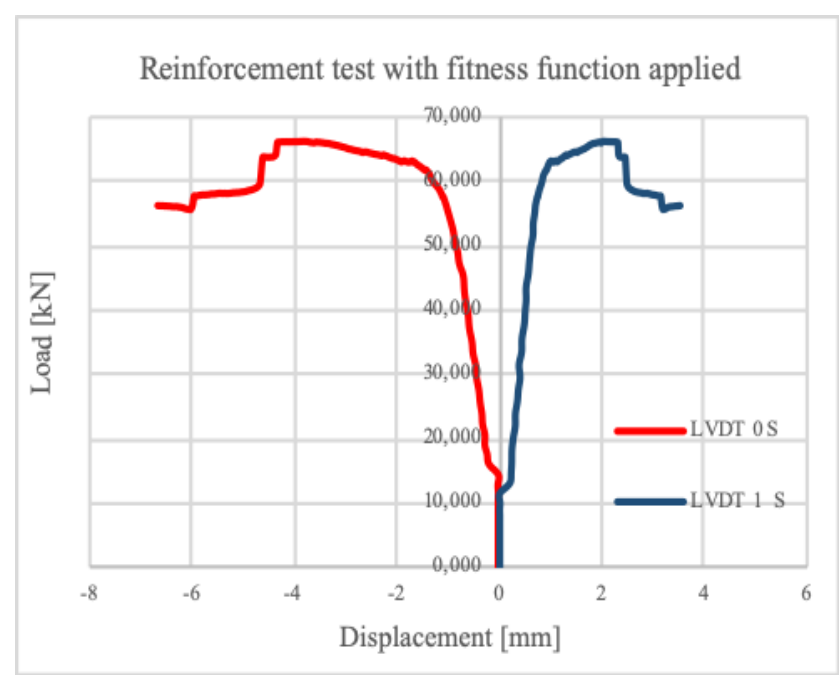

Figure 17. Load vs. displacement diagrams following the application of the fitness function.

For the first specimen, which was tested until collapse occurred, the experimental diagonal compression tests obtained a shear strength of $0.81 \mathrm{MPa}$, while the lowering displacement of the steel plate of the testing machine was $11.526 \mathrm{~mm}$. The second masonry wall was subjected to diagonal compression tests in two distinct phases. Here, the specimen was first damaged and the test stopped when the first cracks appeared before the specimen was repaired using B-FRCM and the test repeated until collapse. The shear strengths obtained here were $0.73 \mathrm{MPa}$ and $1.04 \mathrm{MPa}$, respectively. These results indicate how, following the strengthening of the specimen with B-FRCM, the shear strength underwent an increase of $43 \%$ in relation to the unreinforced case, which highlights the importance of fibre reinforcement for increasing the load-bearing capacity in this type of structure. However, both values were higher than those generally obtained for common masonry walls, while the cracks that formed were consistent with those expected in this type of test.

Figure 18 shows the location of the cracks developed during the testing of the first specimen following the attainment of the maximum load. On both sides of the masonry wall, cracks developed through the mortar, parallel both to each other and to the direction of the load application, while they barely affected the fictile tubules. The numerical simulation demonstrated good agreement in terms of the load displacement diagrams, albeit with some minor discrepancies, while the crack development largely mirrored that obtained in the experimental test. In addition, the simulation of the damage in the wall obtained via the numerical model largely corresponded to the experimental results, while more cracks appeared at the top as well as four single cracks originating at the middle section of each timber beam. Overall, the model was highly similar to the actual situation, with the four small cracks noted above appearing in the back of the wall.

The displacement of the upper plate of the testing machine obtained via the numerical model was compared with the experimental results to evaluate their compatibility. The linearity variation of the LVDT measurement in relation to the nominal values was $\pm 0.288 \mathrm{~mm}$, while in the experimental case, the measured displacement was $11.526 \pm 0.866 \mathrm{~mm}$ and the cover coefficient $=3$. The displacement estimated by the numerical model was compatible with that obtained via the experimental tests $(11.700 \mathrm{~mm})$. 
The proposed AS was composed of various LVDTs, which were used for monitoring the horizontal and vertical displacement, and several strain gauges, used for monitoring the strain. The transducers were connected to a Spider-8 DAQ, which transmitted the data to a computer. All the data acquired were then processed in real time using a spline fitness function in order to remove the disturbance caused by a noise resulting from the DAQ. In addition, a numerical model for the construction techniques in question was created in order to initiate real-time analysis in relation to the data recorded by the SHM system.

\section{ACKNOWLEDGEMENTS}

The authors thank the engineers of the NGT Test laboratory, Gennaro Angotti, Cinzia Angotti and Dino Padula, for their support in the tests.

\section{REFERENCES}

[1] F. Lamonaca, P. F. Sciammarella, C. Scuro, D. L. Carnì, R. S Olivito, Internet of things for structural health monitoring, 2018 Workshop on Metrology for Industry 4.0 and IoT, Brescia, Italy, 16-18 April 2018, pp. 95-100.

DOI: $10.1109 /$ METROI4.2018.8439038

[2] R.S. Olivito, S. Porzio, C. Scuro, D.L. Carnì, F. Lamonaca, SHM systems applied to the built heritage inventory at the territorial scale. A preliminary study based on the CARTIS approach, IMEKO TC4 International Conference on Metrology for Archaeology and Cultural Heritage, Florence, Italy, 4-6 December 2019, pp. 53-58. Online [Accessed 30 March 2021] https://www.imeko.org/publications/tc4-Archaeo2019/IMEKO-TC4-METROARCHAEO-2019-10.pdf

[3] A. Barontini, M. G. Masciotta, L. F. Ramos, P. Amado-Mendes, P. B. Lourenço, An overview on nature-inspired optimization algorithms for structural health monitoring of historical buildings, Procedia Engineering 199 (2017), pp. 3320-3325.

DOI: $10.1016 /$ j.proeng.2017.09.439

[4] C.R. Farrar, K. Worden, An introduction to structural health monitoring, Philosophical Transactions of the Royal Society of London A: Mathematical, Physical and Engineering Sciences 365 (2007), pp. 303-315.

DOI: $10.1098 /$ rsta.2006.1928

[5] X-H. Zhang, Y-L. Xu, S. Zhu, S. Zhan, Dual-type sensor placement for multi-scale response reconstruction, Mechatronics 24(4) (2014), pp. 376-384.

DOI: $10.1016 / \mathrm{j} . \mathrm{mech}$ atronics.2013.05.007

[6] C. Scuro, P. F. Sciammarella, F. Lamonaca, R. S. Olivito, D. L. Carni, Io'T for structural health monitoring, IEEE Instrumentation \& Measurement Magazine 21(6) (2018), pp. 4-14. DOI: 10.1109/MIM.2018.8573586

[7] F. Lamonaca, R. S. Olivito., S. Porio, D. L. Carnì, C. Scuro, Structural health monitoring system for masonry historical construction, Proc. of International Conference on Metrology for Archaeology and Cultural Heritage METROARCHEO 2018, Cassino, Italy, 22 - 24 October 2018, pp. 330-335.

DOI: $10.1109 /$ MetroArchaeo43810.2018.9089776

[8] A. Pierdicca, F. Clementi, D. Isidori, E. Concettoni, C. Cristalli, S. Lenci, Numerical model upgrading of a historical masonry palace monitored with a wireless sensor network, International Journal of Masonry Research and Innovation 1(1) (2016), pp. 74-98. DOI: $10.1504 /$ IJMRI.2016.074748

[9] R. Kitchin, Big Data, new epistemologies and paradigm shifts, Big Data \& Society 1(1) (2014), pp. 1-12. DOI: $10.1177 / 2053951714528481$

[10] E. Poletti, G. Vasconcelos, Seismic behaviour of traditional timber frame walls: experimental results on unreinforced walls, Bull Earthquake Eng. 13 (2015), pp.885-916. DOI: $10.1007 / \mathrm{s} 10518-014-9650-9$
[11] E. Poletti, G. Vasconcelos, J. M. Branco, A. M. Koukouviki, Performance evaluation of traditional timber joints under cyclic loading and their influence on the seismic response of timber frame structures, Construction and Building Materials 127 (2016), pp. 321-334.

DOI: $10.1016 /$ j.conbuildmat.2016.09.122

[12] G. Vasconcelos, E. Poletti, E. Salavessa, A. M. Jesus, P. B. Lourenço, P. Pilaon, In-plane shear behaviour of traditional timber walls, Engineering Structures 56 (2013), pp. 1028-1048. DOI: $10.1016 /$ j.engstruct.2013.05.017

[13] R. S. Olivito, R. Codispoti, C. Scuro, A seismic analysis for masonry constructions: The different schematization methods of masonry walls, AIP Conference Proceedings 1906(1) (2017), p. 090007.

DOI: $\underline{10.1063 / 1.5012364}$

[14] S. Tiberti, C. Scuro, S. Porzio, G. Milani, R. S. Olivito, Postcracking B-FRCM strengthening of a traditional anti-seismic construction technique (casa baraccata): extensive experimental investigations, Key Engineering Materials 817 (2019), pp. 634-641. DOI: $10.4028 /$ www.scientific.net/KEM.817.634

[15] G. Vivenzio, Istoria e Teoria de' Tremuoti in Generale ed in particolare di quelli della Calabria, e di Messina del 1783, Stamperia Regale, Naples, 1783, ISBN-13: 978-1273440243.

[16] S. Tiberti, C. Scuro, R. Codispoti, R. S. Olivito, G. Milani, Experimental and numerical analysis of historical aseismic construction system, in: Structural Analysis of Historical Constructions, Springer, Cham., 2019, ISBN 978-3-319-99440-6, pp. 910-918.

[17] C. Scuro, D. L. Carnì, F. Lamonaca, R. S. Olivito, G. Milani, An innovative structural health monitoring system for the preliminary study of an ancient anti-seismic construction technique, IMEKO TC4 International Conference on Metrology for Archaeology and Cultural Heritage, Florence, Italy, 4-6 December 2019, pp. 43-47. Online [Accessed 30 March 2021]

https://www.imeko.org/publications/tc4-Archaeo2019/IMEKO-TC4-METROARCHAEO-2019-8.pdf

[18] L. Marcheggiani, F. Clementi, A. Formisano. Static and dynamic testing of highway bridges: a best practice example, Journal of Civil Structural Health Monitoring 10(1) (2020), pp. 43-56. DOI: $10.1007 /$ s13349-019-00368-1

[19] A. Formisano, G. Di Lorenzo, L. Krstevska, R. Landolfo, FEM model calibration of experimental environmental vibration tests on two churches hit by L'Aquila earthquake, International Journal of Architectural Heritage 14 (2020), pp. 1-19. DOI: $10.1080 / 15583058.2020 .1719233$

[20] G. Di Lorenzo, A. Formisano, L. Krstevska, R. Landolfo, Ambient vibration test and numerical investigation on the St. Giuliano church in Poggio Picenze (L'Aquila, Italy), Journal of Civil Structural Health Monitoring 9(4) (2019), pp. 477-490. DOI: $10.1007 / \mathrm{s} 13349-019-00346-7$

[21] A. Formisano, L. Krstevska, G. Di Lorenzo, R. Landolfo, Experimental ambient vibration tests and numerical investigation on the Sidoni Palace in Castelnuovo of San Pio (L'Aquila, Italy), Int. J. Masonry Research and Innovation 3(3) (2018), p. 269. DOI: $10.1504 /$ IJMRI.2018.093487

[22] C. Calderini, S. Cattari, S. Lagomarsino, In-plane strength of unreinforced masonry piers, Earthquake Engineering and Structural Dynamics 38(2) (2009), pp. 243-267.

DOI: $10.1002 /$ eqe. 860

[23] W. Mann, H. Müller, Failure of shear-stressed masonry - An enlarged theory, tests and application to shear-walls, Proc. of the International Symposium on Load-Bearing Brickwork, London, UK, 1980, pp. 1-13.

[24] V. Turnšek, F. Čačovič, Some experimental results on the strength of brick masonry walls, Proc. of the $2^{\text {nd }}$ International Brick Masonry Conference, Stoke-on-Trent, UK, 1970, pp. 149-156.

[25] C. Calderini, S. Cattari, S. Lagomarsino, Identification of the shear mechanical parameters of masonry piers from diagonal compression test, $11^{\text {th }}$ Canadian Masonry Symposium, Toronto, Canada, 2009. 
[26] C. Calderini, S. Cattari, S. Lagomarsino, The use of the diagonal compression test to identify the shear mechanical parameters of masonry, Construction and Building Materials 24(5) (2010), pp. 677-685.

DOI: $10.1016 /$ j.conbuildmat.2009.11.001

[27] S. Tiberti, C. Scuro, R. Codispoti, R.S. Olivito, G. Milani, Masonry structures built with fictile tubules: Experimental and numerical analyses, AIP Conference Proceedings, 1906(1) (2017), p. 090010 DOI $10.1063 / 1.5012367$

[28] P. Frezza, Construction System of Earthquake-Resistant Houses, Italian Patent 103254, 1909.

[29] American Society for Testing and Materials, ASTM E519/E519M-15, Standard Test Method for Diagonal Tension (Shear) in Masonry Assemblages, 2015. DOI: $10.1520 /$ E0519 E0519M-15

[30] R. S. Olivito, R. Codispoti, C. Scuro, S. Porzio, Experimental evaluation of the adhesion of a FRCM-tuff strengthening system, Procedia Structural Integrity 12 (2018), pp. 594-601. DOI: $10.1016 /$ j.prostr.2018.11.059

[31] B. de Vries, J. M. Harink, Generation of a construction planning from a 3D CAD model, Automation in Construction 16(1) (2007), pp. 13-18.

DOI: https://10.1016/j.autcon.2005.10.010

[32] P. B. Lourenço, Recent advances in masonry structures: micromodelling and homogenisation, in: Multiscale Modeling in Solid Mechanics: Computational Approaches. U. Galvanetto, M. H. F. Aliabadi (editors). Imperial College Press, London, United Kingdom, 2009, ISBN-10: 184816307X, pp. 251-294.

[33] P. Lonetti, A. Pascuzzo, A. Davanzo, Dynamic behavior of tiedarch bridges under the action of moving loads, Mathematical Problems in Engineering 2016 (2016), p. 17. DOI: $\underline{10.1155 / 2016 / 2749720}$

[34] S. Tiberti, M. Acito, G. Milani, Comprehensive FE numerical insight into Finale Emilia Castle behavior under 2012 Emilia
Romagna seismic sequence: Damage causes and seismic vulnerability mitigation hypothesis, Engineering Structures 117 (2016), pp. 397-421.

DOI: $10.1016 /$ j.engstruct.2016.02.048

[35] A. Hillerborg, M. Modéer, P. E. Petersson, Analysis of crack formation and crack growth in concrete by means of fracture mechanics and finite elements, Cement and Concrete Research 6(6) (1976), pp. 773-781

DOI: $10.1016 / 0008-8846(76) 90007-7$

[36] J. G. Rots, J. Blaauwendraad, Crack models for concrete, discrete or smeared? Fixed, multi-directional or rotating? HERON 34(1) (1989). Online [Accessed 30 March 2021] http://resolver.tudelft.nl/uuid:0a401939-2938-4f9d-a395b6a6652b2cd9

[37] HBM LVDT WA-T Data sheet. Online [Accessed 30 March 2021] https://www.hbm.com/en/3059/wa-t-inductive-displacementtransducer-probe/

[38] HBM Spider-8 Data sheet. Online [Accessed 30 March 2021] https://www.hbm.com/en/6251/product-literature-archive/

[39] BIPM, Guide to the Expression of Uncertainty in Measurement (GUM) (BIPM, IEC, IFCC, ILAC, ISO, IUPAC, IUPAP, and OIML), JCGM, Geneva, 1993, ISBN 92-67-10188-9.

[40] A. Katsuki, T. Sajima, H. Murakami, A. M. Hazrat, O. Ohnishi, K. Akashi, Development of a laser-guiding-type deep small-sized hole-measurement system: Measurement accuracy, Precision Engineering 63 (2020), pp.18-32. DOI: $10.1016 /$ i.precisioneng.2019.12.012

[41] S. Shi, B. Muralikrishnan, V. Lee, D. Sawyer, Methods to improve the dimensional measurement accuracy of a motion tracking system, Optics and Lasers in Engineering 130 (2020), p.106092. DOI: $10.1016 /$ i.optlaseng.2020.106092 